\title{
KAJIAN KESELAMATAN DAN KESEHATAN KERJA BENGKEL DI JURUSAN PENDIDIKAN TEKNIK SIPIL DAN PERENCANAAN FAKULTAS TEKNIK UNY
}

\author{
Nur Hidayat, Indah Wahyuni \\ Pendidikan Teknik Sipil dan Perencanaan FT UNY \\ Email: nurhidayat@uny.ac.id
}

\begin{abstract}
The objective of this study was to analyse: (1) the plan (2) the implementation, and (3) the evaluation of the Occupational Safety and Health (OSH) management in the workshop of the Department of Civil Engineering and Planning Education, Faculty of Engineering, Yogyakarta State University (YSU). This study was categorised into descriptive study that scientifically explained the workplace environment of the workshop specifically in terms of the OSH management. The data collection techniques used observations, interviews and questionnaires. The data of this study was analysed descriptively. This study presented the detailed descriptions of the collected data in the field. The results revealed (1) It is crucial to develop a more systematic OSH management plan in the workshop of the Department of Civil Engineering and Planning Education, Faculty of Engineering, YSU (2) the planning policies and the implementation of the OSH management need a continual improvement and (3) the evaluation of the OSH management should be conducted simultaneously by the stakeholders, the lecturers and the technicians. (4) The OSH policy in the practices should be properly organised to promote the OSH culture in the workshop. (5) The OSH management control and review were prioritised for fostering the effectiveness of the OSH management implementation.
\end{abstract}

Keywords: occupational safety and health, OSH culture, OSH management system

\begin{abstract}
ABSTRAK
Penelitian ini bertujuan untuk mengetahui perencanaan, pelaksanaan, dan evaluasi Keselamatan dan Kesehatan Kerja (K3) di Bengkel Jurusan Pendidikan Teknik Sipil dan Perencanaan FT UNY. Penelitian ini merupakan penelitian deskriptif (descriptive reasearch) yang memaparkan secara ilmiah keadaan di lingkungan bengkel khususnya mengenai aspek K3. Metode pengumpulan data menggunakan observasi, wawancara, dan angket. Analisis data menggunakan analisis deskriptif. Penelitian ini mendeskripsikan secara detail terhadap apa yang ditemukan dalam pengambilan data. Hasil penelitian ini menunjukkan bahwa: (1) Perencanaan K3 di bengkel masih perlu diperbaiki agar lebih matang dan sistematis. (2) Pelaksanaan K3 di bengkel masih perlu ditingkatkan terkait dengan kebijakan perencanaan dan pelaksanaan. (3) Evaluasi K3 di bengkel perlu dilakukan secara simultan oleh pihak penentu kebijakan, dosen, dan teknisi. (4) Budaya K3 di bengkel masih perlu ditingkatkan dengan penetapan kebijakan mengenai K3 dalam proses pembelajaran praktik. (5) Faktor peninjauan dan peningkatan kinerja K3 perlu dilakukan untuk menjamin kesesuaian dan efektivitas penerapan sesuai Sistem Manajemen K3.
\end{abstract}

Kata kunci: budaya K3, keselamatan dan kesehatan kerja, sistem manajemen K3

\section{PENDAHULUAN}

Keselamatan dan Kesehatan Kerja (K3) merupakan bagian penting pada suatu pekerjaan di laboratorium, perusahaan, maupun bengkel. Resiko kegagalan (risk of failures) akan selalu ada pada suatu aktifitas pekerjaan yang disebabkan perencanaan yang kurang sempurna, pelaksanaan yang kurang cermat, maupun akibat yang tidak disengaja. Salah satu resiko pekerjaan yang dapat terjadi adalah adanya kecelakaan kerja. Kecelakaan kerja (work accident) akan mengakibatkan adanya efek kerugian (loss) seberapapun jumlahnya. Oleh karena itu sedapat mungkin kecelakaan kerja harus dicegah, apabila memungkinan dapat dihilangkan, atau setidaktidaknya dikurangi dampaknya.

Penanganan masalah keselamatan kerja di tempat kerja harus dilakukan secara serius. Penanganan di tempat kerja tersebut juga 
termasuk di lembaga pendidikan seperti di lingkungan Jurusan Pendidikan Teknik Sipil dan Perencanaan FT UNY yang terdapat bengkelbengkel sebagai tempat praktik. Semua orang (dosen, teknisi, dan mahasiswa) yang terlibat di bengkel harus ikut menjaga keselamatan dan kesehatan kerja. Urusan K3 tidak hanya sekedar pemasangan spanduk, poster, atau semboyan. Lebih jauh dari itu K3 harus menjadi nafas setiap pekerja yang berada di tempat kerja. Kuncinya adalah kesadaran akan adanya resiko bahaya dan perilaku yang merupakan kebiasaan untuk bekerja secara sehat dan selamat. Kebiasaan bekerja seperti inilah yang sering terlupakan oleh praktikan ketika di bengkel. Untuk itu, kesadaran bekerja secara selamat dan sehat hendaknya sudah menjadi kebiasaan.

Alasan efisiensi kerja sering kali menyebabkan terjadi kelalaian terhadap bahaya yang mengancam, misalnya penggunaan alat yang rusak yang dapat menimbulkan bahaya atau kecelakaan kerja. Selain itu, keterbatasan biaya juga sering menjadi alasan penggunaan peralatan yang terkesan apa adanya. Upaya optimalisasi memang diperlukan tetapi harus memenuhi syarat keselamatan dan kesehatan kerja. Banyak pihak yang kurang menyadari bahwa biaya yang terjadi akibat adanya suatu kecelakaan kerja dapat jauh lebih besar dari pada pencegahannya. Besarnya biaya untuk rehabilitasi kecelakaan dan penyakit akibat kerja harus ditekan salah satunya dengan upaya pencegahan maupun pengendalian.

Tarwaka (2008) menjelaskan pengendalian resiko dapat mengikuti Pendekatan Hirarki Pengendalian (Hirarchy of Control). Hirarki pengendalian resiko adalah suatu urutan-urutan dalam pencegahan dan pengendalian resiko yang mungkin timbul terdiri dari beberapa tingkatan secara berurutan. Dalam hirarki pengendalian resiko terdapat 2 (dua) pendekatan, yaitu pendekatan long term gain (pengendalian berorientasi jangka panjang dan bersifat permanen) dan Pendekatan short term gain (pengendalian berorientasi jangka pendek dan bersifat temporari atau sementara). Pencegahan maupun pengendalian tersebut dilakukan untuk menghindari akibat yang muncul, baik yang bersifat sementara maupun yang permanen.

Hubungan K3 dengan akibat yang dapat ditimbulkan dapat diidentifikasi sesuai potensi bahaya yang ada. Potensi bahaya merupakan sesuatu yang berpotensi dapat menyebabkan terjadinya kerugian, kerusakan, cedera, sakit, kecelakaan, atau bahkan dapat menyebabkan kematian yang berhubungan dengan proses dan sistem kerja. Soehatman (2009) menjelaskan identifikasi bahaya merupakan suatu teknik komprehensif untuk mengetahui potensi bahaya dari suatu bahan, alat, atau sistem. Bahaya dapat diketahui dengan berbagai cara dan dari berbagai sumber antara lain dari peristiwa atau kecelakaan yang terjadi, pemeriksaan ke tempat kerja, melakukan wawancara dengan pekerja di lokasi kerja, informasi dari pabrik atau asosiasi industri, data keselamatan bahan (material safety data sheet) dan lainnya.

Dalam PP RI No 50 Tahun 2012 tentang Penerapan Sistem Manajemen Keselamatan dan Kesehatan Kerja (SMK3) dijelaskan bahwa terdapat beberapa aspek SMK3, yaitu meliputi: penetapan kebijakan K3, perencanaan K3, pelaksanaan $\mathrm{K} 3$, pemantauan serta evaluasi $\mathrm{K} 3$, dan peninjauan serta peningkatan K3. Selain itu, sistem manajemen K3 telah diatur menurut Peraturan Menteri Tenaga Kerja Republik Indonesia, yaitu Permenaker No.05/MEN/1996, yang menyatakan bahwa Sistem Manajemen Keselamatan dan Kesehatan Kerja (SMK3) merupakan bagian dari sistem manajemen secara keseluruhan, yang meliputi struktur organisasi, perencanaan, tanggung jawab, pelaksanaan, prosedur, proses, dan sumber daya yang dibutuhkan bagi pengembangan, penerapan, pencapaian, pengkajian, dan pemeliharaan kebijakan keselamatan dan kesehatan kerja dalam pengendalian resiko yang terjadi seminimal mungkin berkaitan dengan kegiatan kerja guna terciptanya tempat kerja yang aman efisien dan produktif.

Mario (2007) menyatakan bahwa dalam membuat kurikulum, SMK telah memasukkan perencanaan K3 sebagai pedoman pelaksanaan pembelajaran praktik. Pengawasan dan juga 
pembinaan guru dalam pelaksanaan cukup baik terkait dengan pekerjaan yang dilakukan. Salah satu kekurangannya adalah evaluasi K3 yang tidak sepenuhnya dilakukan dalam pelaksanaan pembelajaran. Hal ini terkait dengan kebijakan dan penyempurnaan pengembangan evaluasi sebagai dasar pelaksanaan pembelajaran yang akan datang. Metode sistem pelaporan hendaknya dapat dilakukan sebagai usaha dalam rehabilitasi dan penyempurnaan kinerja atau standarisasi kerja.

Putut (2007) menjelaskan (a) Jenis bahaya yang terdapat di bengkel atau laboratorium SMK meliputi sembilan kelompok pekerjaan, yaitu yang berkaitan dengan penanganan bahan, penggunaan alat-alat tangan, perlindungan mesin, desain tempat kerja, pencahayaan, cuaca kerja, pengendalian bahaya bising, getaran dan listrik, fasilitas pekerja, dan organisasi kerja; (b) Rerata tingkat resiko bahaya yang terdapat di bengkel atau laboratorium SMK meliputi: tidak berbahaya (68 kasus atau 54\%), perlu tindakan penanganan (43 kasus atau 34\%), dan perlu prioritas tindakan penanganan (10 kasus atau $8 \%$ ), sedangkan lainnya sebesar $4 \%$ atau 6 kasus tidak ada datanya; (c) Pengendalian bahaya dengan urgensi tinggi pada kondisi beresiko untuk dilakukan prioritas tindakan perbaikan pada kasus yang perlu tindakan perbaikan, sedangkan yang terakhir adalah mempertahankan dan memperbaiki kondisi pada kasus yang tidak perlu tindakan perbaikan; (4) Rekomendasi untuk perbaikan kondisi dilakukan dengan tahapan sebagai berikut: menetapkan sasaran, memilih pendekatan, menetapkan prosedur serta melakukan evaluasi terus menerus terhadap kondisi $\mathrm{K} 3$ di bengkel atau laboratorium.

Indrayani dan Ika (2014) menyatakan bahwa penilaian terhadap tingkat pengetahuan K3 dari dosen, laboran, teknisi, maupun mahasiswa pada pembelajaran di laboratorium dan bengkel Politeknik Negeri Sriwijaya menunjukkan bahwa masih perlu ditingkatkan. Ketersediaan peralatan K3 di bengkel masih sangat kurang jika dibandingkan dengan rasio orang yang menggunakannya. Apabila dikaji dari aspek manajemen K3, penerapannya sudah dilaksanakan akan tetapi masih perlu diperbaiki. Pada dasarnya sistem manajemen keselamatan dan kesehatan kerja perlu direncanakan sebaik mungkin. Perencanaan tersebut hendaknya disusun berdasar keadaan nyata yang ada di tempat kerja. Keadaan lingkungan bengkel maupun peralatan harus diketahui dengan jelas untuk mengetahui potensi bahaya yang dapat ditimbulkan. Selain itu, pelaksanaan K3 harus dilakukan sesuai rencana yang telah disusun. Pelaksanaan tersebut hendaknya dilakukan oleh semua pihak yang terlibat di lingkungan bengkel, yaitu dosen, teknisi, dan mahasiswa.

Apabila pelaksanaan telah sesuai dengan yang telah direncanakan, potensi kecelakaan diharapkan akan dapat dikurangi dan bahkan dihilangkan. Tahapan dari sistem manajemen K3 yang selanjutnya harus dilakukan adalah evaluasi. Proses ini hendaknya terus dilakukan secara bertahap dan terus menerus baik tiap semester maupun tiap tahun. Dari tahap evaluasi ini diharapkan dapat mengetahui kekurangan dari pelaksanaan sehingga dapat disusun perencanaan yang lebih baik. Hal-hal tersebut yang menjadi latar belakang dilakukannya penelitian ini. Penelitian ini bertujuan untuk mengetahui perencanaan, pelaksanaan, dan evaluasi K3 di Bengkel Jurusan Pendidikan Teknik Sipil dan Perencanaan FT UNY.

\section{METODE}

Penelitian ini merupakan penelitian deskriptif (descriptive reasearch). Dalam penelitian ini, peneliti mendeskripsikan secara ilmiah keadaan di lingkungan bengkel Jurusan Teknik Sipil dan Perencanaan Fakultas Teknik Universitas Negeri Yogyakarta yang erat kaitannya dengan Keselamatan dan Kesehatan Kerja (K3). Penelitian ini tidak memberikan perlakuan terhadap apa yang diteliti tetapi hanya sebatas mendeskripsikan secara detail terhadap apa yang ditemukan dalam pengambilan data. Metode pengumpulan data dalam penelitian ini menggunakan observasi, wawancara, dan angket. Observasi dilakukan langsung ke 
bengkel-bengkel yang ada di Jurusan Teknik Sipil dan Perencanaan FT UNY. Wawancara dilakukan dengan dosen maupun teknisi untuk memperoleh data pendukung penelitian. Selain itu, data dari angket mengenai K3 diberikan kepada responden. Data tersebut menggunakan skala Likert.

Instrumen penelitian disusun berdasarkan kiri-kisi instrumen yang meliputi perencanaan, pelaksanaan, dan evaluasi. Instrumen ini berbentuk angket pernyataan yang diisi oleh dosen, teknisi, dan mahasiswa. Responden diminta memberikan penilaian maupun tanggapan yang ada di lembar instrumen. Penilaian berupa isian skor 5 (Sangat Baik), 4 (Baik), 3 (Cukup Baik), 2 (Kurang Baik), dan 1 (Sangat Kurang Baik). Kisi-kisi instrumen yang telah disusun berdasarkan indikator yang dinyatakan oleh Ridley (2009) disajikan dalam Tabel 1 sebagai berikut:

Tabel 1. Kisi-kisi Instrumen

\begin{tabular}{cllc}
\hline Faktor & \multicolumn{1}{c}{ Indikator } & \multicolumn{1}{c}{ Nomor Butir Pernyataan } & Jumlah Butir \\
\hline Perencanaan & Komitmen terhadap K3 & $1,2,3,4,5$, dan 6 & 6 \\
Pelaksanaan & Komunikasi & 7,8, dan 9 & 3 \\
& Kompetensi & $10,11,12,13$, dan 14 & 5 \\
& Lingkungan kerja & $15,16,17,18,19,20,21,22$, & 9 \\
& Peralatan & dan 23 & 6 \\
& Keterlibatan mahasiswa dan & $24,25,26,27,28$, dan 29 & 4 \\
Evaluasi & teknisi & $30,31,32$, dan 33 & 2 \\
& Program penilaian Resiko & 34 dan 35 & 2 \\
& Identifikasi bahaya & 36 dan 37 & 1 \\
& Strategi Pencegahan & 38 & 38 \\
\hline
\end{tabular}

Angket tersebut diisi oleh 30 mahasiswa secara acak untuk masing-masing bengkel. Dari 30 mahasiswa tersebut, 15 mahasiswa adalah mahasiswa semester I serta 15 mahasiswa semester III dan V. Pemilihan mahasiswa pada semester I didasarkan pada pertimbangan bahwa mahasiswa pada semester tersebut sedang melakukan praktik di tiga bengkel sehingga mengetahui kondisi K3 di bengkel-bengkel tersebut saat penelitian dilakukan. Pemilihan mahasiswa semester III dan V didasarkan pada pertimbangan bahwa mahasiswa pada semester tersebut sudah pernah mengalami hampir secara keseluruhan kondisi K3 di bengkel.

Analisis data yang digunakan dalam penelitian ini menggunakan analisis deskriptif. Hasil observasi dan wawancara dipaparkan dalam hasil penelitian. Data angket dianalisis secara kuantitatif. Data tersebut berupa rerata setiap indikator (skala 5) yang di konversikan sebagaimana pada Tabel 2 sebagai berikut:

Tabel 2. Konversi Skor Ideal

\begin{tabular}{ccc}
\hline Nilai & Skor & Kategori \\
\hline 5 & $\mathrm{X}>M_{i}+1,80 \mathrm{SD}_{i}$ & Sangat Baik \\
4 & $M_{i}+0,60 \mathrm{SD}_{i}<\mathrm{X} \leq \mathrm{M}_{i}+1,80 \mathrm{SD}_{i}$ & Baik \\
3 & $M_{i}-0,60 \mathrm{SD}_{i}<\mathrm{X} \leq \mathrm{M}_{i}+0,60 \mathrm{SD}_{i}$ & Cukup Baik \\
2 & $M_{i}-1,80 \mathrm{SB}_{i}<\mathrm{X} \leq M_{i}-0,60 \mathrm{SD}_{i}$ & Kurang Baik \\
1 & $\mathrm{X} \leq M_{i}-1,80 \mathrm{SD}_{i}$ & Sangat Kurang Baik \\
\hline
\end{tabular}

Selanjutnya perolehan skor dalam data konversi skor ideal tersebut dimasukkan dalam kategori penilaian akhir Sangat Baik, Baik,
Cukup Baik. Kurang Baik, atau Sangat Kurang Baik seperti disajikan pada Tabel 3 sebagai berikut: 
Tabel 3. Kategori Skor

\begin{tabular}{ccc}
\hline Nilai & Skor & Kategori \\
\hline 5 & $\mathrm{X}>4,21$ & Sangat Baik \\
4 & $3,40<\mathrm{X} \leq 4,21$ & Baik \\
3 & $2,60<\mathrm{X} \leq 3,40$ & Cukup Baik \\
2 & $1,79<\mathrm{X} \leq 2,60$ & Kurang Baik \\
1 & $\mathrm{X} \leq 1,79$ & Sangat Kurang Baik \\
\hline
\end{tabular}

\section{HASIL DAN PEMBAHASAN}

Peneliti melakukan observasi secara langsung di tiga bengkel Pendidikan Teknik Sipil dan Perencanaan FT UNY, yaitu di Bengkel
Kayu, Bengkel Plambing, dan Bengkel Batu. Dalam observasi tersebut, peneliti juga melakukan wawancara dengan teknisi bengkel. Observasi yang dilakukan di Bengkel Kayu menghasilkan data pada Tabel 4 berikut:

Tabel 4. Hasil Observasi di Bengkel Kayu

\begin{tabular}{cll}
\hline No & \multicolumn{1}{c}{ Peralatan } & \multicolumn{1}{c}{ Kondisi yang Kurang } \\
\hline 1. Mesin Gergaji Potong berlengan & 1. Tidak ada cover atau pelindung mata pisau \\
2. Mesin Ketam Perata & 2. Tidak ada pengendali gergaji potong \\
& 1. Tidak ada cover atau pelindung mata pisau \\
3. Mesin Ketam Penebal & 2. Adanya kebisingan akibat mesin yang sudah tua \\
4. Mesin Gergaji Belah & 3. Tidak ada penghisab debu pada mesin \\
& 1. Adanya kebisingan akibat mesin yang sudah tua \\
5. Mesin Gergaji Pita & 2. Mata pisau yang sudah tidak halus \\
6. Mesin Pahat & 1. Tidak ada cover atau pelindung mata pisau \\
7. Ketam Listrik Portable & 2. Penahan kunci pengaturan yang sudah tidak akurat \\
8. Gergaji Tangan & 1. Tidak ada cover atau pelindung mata pisau \\
9. Ketam Tangan Manual & 1. Penahan kunci pengaturan yang sudah tidak akurat \\
& 1. Mata pisau yang sudah bergerigi \\
& 1. Mata pisau yang sudah tidak standar antara gergaji \\
& 1. Ketam tangan yang sudah lama \\
10. Pahat tangan & 2. Pengaturan ketam yang sudah tidak berfungsi \\
11. Mesin Bubut Kayu & 3. Mata ketam yang sudah bergerigi \\
& 4. Mata ketam yang sudah pendek akibat sering di \\
& 1. Perinda \\
\hline
\end{tabular}

Selain karena kondisi yang kurang, kondisi mesin di Bengkel Kayu sudah berumur lebih dari 20 tahun. Hal itu mengakibatkan produktivitas mesin sudah tidak maksimal, adanya kebisingan oleh mesin, dan komponen mesin yang sudah tidak lengkap seperti cover pelindung. Tidak adanya peredam kebisingan di bengkel serta tidak adanya penghisap debu dapat mengakibatkan sesak nafas karena debu kayu serta bising mesin kayu. Kecelakaan-kecelakaan kecil juga kadang terjadi di Bengkel Kayu, diantaranya tangan tersayat pahat, jari terpukul palu, dan tangan tertusuk serat kayu. Hasil observasi yang telah dilakukan di Bengkel Plambing disajikan pada Tabel 5 sebagai berikut: 
Tabel 5. Hasil Observasi di Bengkel Plambing

\begin{tabular}{|c|c|c|}
\hline No & Peralatan & Kondisi yang Kurang \\
\hline & Mesin Las Listrik & Terdapat tiga mesin las listrik: \\
\hline & & $\begin{array}{l}\text { 1. Sambungan kabel antara sumber listrik dengan mesin las } \\
\text { kurang kuat }\end{array}$ \\
\hline & & 2. Meja kerja yang terdapat kerak-kerak hasil las \\
\hline & & 3. Tuas pengontrol arus listrik tidak berfungsi dengan baik \\
\hline & & 4. Penjepit elektroda yang sudah longgar \\
\hline \multirow[t]{2}{*}{2.} & Mesin Pemotong Plat Hidrolis & 1. Area pemotongan merupakan jalur lalu lintas \\
\hline & & 2. Kabel dari sumber listrik yang berada di jalur lalu lintas \\
\hline 3. & Pemotong Plat Manual & 1. Area alat pemotong merupakan area kerja alat pelipat \\
\hline 4. & Mesin Pemotong Besi & $\begin{array}{l}\text { 1. Area pengoperasian alat rol penggulung tidak berada dalam } \\
\text { area yang cukup nyaman }\end{array}$ \\
\hline 5. & Pelipat Plat Tipis & $\begin{array}{l}\text { 1. Terdapat penjepit yang kurang kencang pada salah satu alat } \\
\text { pelipat }\end{array}$ \\
\hline 6. & Mesin Gerinda & 1. Pelindung untuk serpihan benda yang digerinda tidak ada \\
\hline & Rol Penggulung & $\begin{array}{l}\text { 1. Area pengoperasian alat rol penggulung tidak berada dalam } \\
\text { area yang steril }\end{array}$ \\
\hline \multirow[t]{2}{*}{8.} & Perangkat Las Gas & Terdapat empat perangkat las gas: \\
\hline & & $\begin{array}{l}\text { 1. Tekanan gas yang berbeda pada masing-masing alat } \\
\text { walaupun bersumber dari tabung yang sama. } \\
\text { 2. Sirkulasi udara yang kurang baik. } \\
\text { 3. Pemantik api tidak tersedia pada masing-masing alat las }\end{array}$ \\
\hline & Mesin Bor & $\begin{array}{l}\text { 1. Pelindung mata bor untuk serpihan sisa pengeboran tidak } \\
\text { ada }\end{array}$ \\
\hline & & 2. Plat yang di bor dapat ikut berputar bersama mata bor \\
\hline
\end{tabular}

Selain karena kondisi yang kurang diatas, kecelakaan-kecelakaan kecil juga kadang terjadi di Bengkel Plambing, diantaranya tangan tergores plat, jari terpukul palu, tangan terbentur snei karena terlalu kuat ketika mengayun, sesak nafas karena asap, dan bising mesin plambing. Hasil observasi yang dilakukan di Bengkel Batu, peneliti tidak menemukan potensi kecelakaan kerja yang berat. Hal tersebut karena di Bengkel Batu tidak terdapat peralatan besar yang dapat menimbulkan potensi kecelakaan. Hasil observasi tersebut didukung oleh informasi dari teknisi Bengkel Batu yang menyatakan bahwa tidak terdapat potensi kecelakaan maupun kecelakaan berat yang telah terjadi di Bengkel Batu. Kecelakaan kerja yang pernah terjadi di Bengkel Batu hanya kecelakaan-kecelakaan ringan, diantaranya: iritasi pada telapak tangan, tangan tergores paku, mata terkena debu, dan terkilir karena mengangkat beban terlalu berat. Uji validitas dilakukan untuk mengetahui validnya instrumen yang digunakan. Dalam uji validitas ini, diuji 38 butir pernyataan dengan jumlah responden $90(\mathrm{~N}=90)$. Data tersebut dinyatakan valid apabila $r$ tabel yang diperoleh dengan taraf signifikansi $1 \%$ adalah di atas 0,2673. Dari data yang diperoleh setelah diuji validitasnya menggunakan SPSS versi 22 didapatkan semua skor berada diatas 0,2673. Berdasarkan hasil tersebut dapat disimpulkan bahwa 38 butir pernyataan yang digunakan dalam angket dinyatakan valid.

Selain uji validitas di atas, butir pernyataan juga diuji reliabilitasnya. Uji reliabilitas ini juga menguji 38 butir pernyataan dengan jumlah responden $90(\mathrm{~N}=90)$. Data tersebut dinyatakan reliabel apabila $r$ tabel yang diperoleh dengan taraf signifikansi $1 \%$ adalah diatas 0,2673 . Dari data yang diperoleh setelah uji reliabilitas menggunakan SPSS versi 22 didapatkan skor 0,924. Berdasarkan hasil tersebut dapat disimpulkan bahwa 38 butir pernyataan dinyatakan reliabel atau terpercaya. Indikator komitmen pada perencanaan K3 di Bengkel Kayu reratanya adalah 3,64. Rerata tersebut berada dalam rentang nilai $3,40<x \leq 4,2$ sehingga masuk dalam kategori baik. Indikator komitmen pada perencanaan K3 di Bengkel Kayu disajikan dalam Tabel 6 sebagai berikut: 
Tabel 6. Indikator Komitmen (Perencanaan) K3 di Bengkel Kayu

\begin{tabular}{cccccc}
\hline Jawaban $(\mathrm{N})$ & Frekuensi $(\mathrm{F})$ & N.F & Prosentase (\%) & Rerata & Kategori \\
\hline 1 & 1 & 1 & 0,56 & & \\
2 & 16 & 32 & 8,89 & 3,64 & Baik \\
3 & 60 & 180 & 33,33 & & \\
4 & 73 & 292 & 40,56 & & \\
5 & 30 & 150 & 16,67 & & \\
Jumlah & 180 & 655 & 100,00 & & \\
\hline
\end{tabular}

Indikator komunikasi pada pelaksanaan

K3 di Bengkel Kayu reratanya adalah 3,74.

Rerata tersebut berada dalam rentang nilai $3,40<\mathrm{x} \leq 4,2$ sehingga masuk dalam kategori baik. Data indikator komitmen pada pelaksanaan K3 di Bengkel Kayu disajikan dalam Tabel 7 .

Tabel 7. Indikator Komunikasi (Pelaksanaan) di Bengkel Kayu

\begin{tabular}{cccccc}
\hline Jawaban $(\mathrm{N})$ & Frekuensi (F) & N.F & Prosentase (\%) & Rerata & Kategori \\
\hline 1 & 6 & 6 & 6,67 & & \\
2 & 5 & 10 & 5,56 & & \\
3 & 19 & 57 & 21,11 & 3,74 & Baik \\
4 & 36 & 144 & 40,00 & & \\
5 & 24 & 120 & 26,67 & & \\
Jumlah & 90 & 337 & 100,00 & & \\
\hline
\end{tabular}

Indikator kompetensi pada pelaksanaan K3 di Bengkel Kayu reratanya adalah 3,93. Rerata tersebut berada dalam rentang nilai $3,40<\mathrm{x} \leq 4,2$ sehingga masuk dalam kategori baik. Indikator kompetensi pada pelaksanaan K3 di Bengkel Kayu disajikan dalam Tabel 8.

Tabel 8. Indikator Kompetensi (Pelaksanaan) di Bengkel Kayu

\begin{tabular}{cccccc}
\hline Jawaban $(\mathrm{N})$ & Frekuensi $(\mathrm{F})$ & N.F & Prosentase $(\%)$ & Rerata & Kategori \\
\hline 1 & 1 & 1 & 0,67 & & \\
2 & 6 & 12 & 4,00 & 3,93 & Baik \\
3 & 34 & 102 & 22,67 & & \\
4 & 70 & 280 & 46,67 & & \\
5 & 39 & 195 & 26,00 & & \\
Jumlah & 150 & 590 & 100,00 & & \\
\hline
\end{tabular}

Indikator lingkungan kerja pada pelaksanaan K3 di Bengkel Kayu reratanya adalah 3,87 diantara rentang nilai 3,40<x $\leq 4,2$ sehingga masuk dalam kategori baik. Data indikator lingkungan kerja pada pelaksanaan K3 di Bengkel Kayu disajikan dalam Tabel 9 sebagai berikut:

Tabel 9. Indikator Lingkungan Kerja (Pelaksanaan) di Bengkel Kayu

\begin{tabular}{cccccc}
\hline Jawaban $(\mathrm{N})$ & Frekuensi (F) & N.F & Prosentase (\%) & Rerata & Kategori \\
\hline 1 & 0 & 0 & 0,00 & & \\
2 & 17 & 34 & 6,30 & 3,87 & Baik \\
3 & 67 & 201 & 24,81 & & \\
4 & 119 & 476 & 44,07 & & \\
5 & 67 & 335 & 24,81 & & \\
Jumlah & 270 & 1046 & 100,00 & & \\
\hline
\end{tabular}

Indikator peralatan pada pelaksanaan K3 di Bengkel Kayu reratanya adalah 3,78. Rerata tersebut berada dalam rentang nilai $3,40<\mathrm{x} \leq 4,2$ sehingga masuk dalam kategori baik. Data indikator peralatan pada pelaksanaan K3 di Bengkel Kayu disajikan dalam Tabel 10 berikut: 
Tabel 10. Indikator Peralatan (Pelaksanaan) di Bengkel Kayu

\begin{tabular}{cccccc}
\hline Jawaban $(\mathrm{N})$ & Frekuensi $(\mathrm{F})$ & N.F & Prosentase $(\%)$ & Rerata & Kategori \\
\hline 1 & 2 & 2 & 1,11 & & \\
2 & 9 & 18 & 5,00 & 3,78 & Baik \\
3 & 51 & 153 & 28,33 & & \\
4 & 82 & 328 & 45,56 & & \\
5 & 36 & 180 & 20,00 & & \\
Jumlah & 180 & 681 & 100,00 & & \\
\hline
\end{tabular}

Indikator keterlibatan mahasiswa pada pelaksanaan K3 di Bengkel Kayu reratanya adalah 3,94 diantara rentang nilai $3,40<\mathrm{x} \leq 4,2$ sehingga masuk dalam kategori baik. Data tersebut disajikan dalam Tabel 11 sebagai berikut:

Tabel 11. Indikator Keterlibatan Mahasiswa (Pelaksanaan) di Bengkel Kayu

\begin{tabular}{cccccc}
\hline Jawaban $(\mathrm{N})$ & Frekuensi $(\mathrm{F})$ & N.F & Prosentase $(\%)$ & Rerata & Kategori \\
\hline 1 & 1 & 1 & 0,83 & & \\
2 & 6 & 12 & 5,00 & 3,94 & Baik \\
3 & 26 & 78 & 21,67 & & \\
4 & 53 & 212 & 44,17 & & \\
5 & 34 & 170 & 28,33 & & \\
Jumlah & 120 & 473 & 100,00 & & \\
\hline
\end{tabular}

Indikator program penilaian resiko pada evaluasi K3 di Bengkel Kayu reratanya adalah 3,83 . Rerata tersebut berada dalam rentang nilai $3,40<\mathrm{x} \leq 4,2$ sehingga masuk dalam kategori baik. Data indikator program penilaian resiko pada evaluasi K3 di Bengkel Kayu disajikan dalam Tabel 12 sebagai berikut:

Tabel 12. Indikator Program Penilaian Resiko (Evaluasi) di Bengkel Kayu

\begin{tabular}{cccccc}
\hline Jawaban $(\mathrm{N})$ & Frekuensi $(\mathrm{F})$ & N.F & Prosentase (\%) & Rerata & Kategori \\
\hline 1 & 0 & 0 & 0,00 & & \\
2 & 5 & 10 & 8,33 & 3,83 & Baik \\
3 & 15 & 45 & 25,00 & & \\
4 & 25 & 100 & 41,67 & & \\
5 & 15 & 75 & 25,00 & & \\
Jumlah & 60 & 230 & 100,00 & & \\
\hline
\end{tabular}

Indikator identifikasi bahaya pada evaluasi K3 di Bengkel Kayu reratanya adalah 3,72 . Rerata tersebut berada dalam rentang nilai $3,40<\mathrm{x} \leq 4,2$ sehingga masuk dalam kategori baik. Data indikator identifikasi bahaya pada evaluasi K3 di Bengkel Kayu disajikan dalam Tabel 13 sebagai berikut:

Tabel 13. Indikator Identifikasi Bahaya (Evaluasi) di Bengkel Kayu

\begin{tabular}{cccccc}
\hline Jawaban $(\mathrm{N})$ & Frekuensi $(\mathrm{F})$ & N.F & Prosentase (\%) & Rerata & Kategori \\
\hline 1 & 0 & 0 & 0,00 & & \\
2 & 4 & 8 & 6,67 & 3,72 & Baik \\
3 & 21 & 63 & 35,00 & & \\
4 & 23 & 92 & 38,33 & & \\
5 & 12 & 60 & 20,00 & & \\
Jumlah & 60 & 223 & 100,00 & & \\
\hline
\end{tabular}

Indikator strategi pencegahan pada evaluasi K3 di Bengkel Kayu reratanya adalah
4,00. Rerata tersebut berada dalam rentang nilai $3,40<\mathrm{x} \leq 4,2$ sehingga masuk dalam kategori 
baik. Data indikator strategi pencegahan pada

Tabel 14 sebagai berikut:

evaluasi K3 di Bengkel Kayu disajikan dalam

Tabel 14. Indikator Strategi Pencegahan (Evaluasi) di Bengkel Kayu

\begin{tabular}{cccccc}
\hline Jawaban $(\mathrm{N})$ & Frekuensi $(\mathrm{F})$ & N.F & Prosentase (\%) & Rerata & Kategori \\
\hline 1 & 0 & 0 & 0,00 & & \\
2 & 1 & 2 & 3,33 & 4,00 & Baik \\
3 & 8 & 24 & 26,67 & & \\
4 & 11 & 44 & 36,67 & & \\
5 & 10 & 50 & 33,33 & & \\
Jumlah & 30 & 120 & 100,00 & & \\
\hline
\end{tabular}

Selain perolehan data di atas, responden juga memberikan komentar yang diantaranya adalah kelengkapan alat yang perlu ditambah, pergantian alat yang sudah tidak layak, penyediaan alat $\mathrm{K} 3$ yang perlu ditambah, penanganan suara mesin yang lebih baik, perlunya penghisap serbuk kayu, penyediaan sirkulasi udara yang lebih baik, pengawasan terhadap penggunaan alat, kondisi ruangan yang sempit, penambahan poster mengenai $\mathrm{K} 3$, dan strategi peningkatan kualitas K3.

Indikator komitmen pada perencanaan K3 di Bengkel Plambing reratanya adalah 3,37. Rerata tersebut berada dalam rentang nilai $2,60<\mathrm{x} \leq 3,40$ sehingga masuk dalam kategori cukup baik. Data indikator komitmen pada perencanaan K3 di Bengkel Plambing disajikan dalam Tabel 15 berikut:

Tabel 15. Indikator Komitmen (Perencanaan) di Bengkel Plambing

\begin{tabular}{cccccc}
\hline Jawaban $(\mathrm{N})$ & Frekuensi $(\mathrm{F})$ & N.F & Prosentase $(\%)$ & Rerata & Kategori \\
\hline 1 & 2 & 2 & 1,11 & & \\
2 & 29 & 58 & 16,11 & 3,37 & Cukup Baik \\
3 & 69 & 207 & 38,33 & & \\
4 & 60 & 240 & 33,33 & & \\
5 & 20 & 100 & 11,11 & & \\
Jumlah & 180 & 607 & 100,00 & & \\
\hline
\end{tabular}

Indikator komunikasi pada pelaksanaan K3 di Bengkel Plambing reratanya adalah 2,81. Rerata tersebut berada dalam rentang nilai $2,60<\mathrm{x} \leq 3,40$ sehingga masuk dalam kategori cukup baik. Data indikator komitmen tersebut disajikan dalam Tabel 16 berikut:

Tabel 16. Indikator Komunikasi (Pelaksanaan) di Bengkel Plambing

\begin{tabular}{cccccc}
\hline Jawaban $(\mathrm{N})$ & Frekuensi $(\mathrm{F})$ & N.F & Prosentase $(\%)$ & Rerata & Kategori \\
\hline 1 & 14 & 14 & 15.56 & & \\
2 & 27 & 54 & 30.00 & 2.81 & Cukup Baik \\
3 & 20 & 60 & 22.22 & & \\
4 & 20 & 80 & 22.22 & 10.00 & \\
5 & 9 & 45 & 100.00 & & \\
Jumlah & 90 & 253 & &
\end{tabular}

Indikator kompetensi pada pelaksanaan K3 di Bengkel Plambing reratanya adalah 3,61. Rerata tersebut berada dalam rentang nilai $3,40<\mathrm{x} \leq 4,2$ sehingga masuk dalam kategori baik. Indikator kompetensi pada pelaksanaan K3 di Bengkel Plambing disajikan dalam Tabel 17. 
Tabel 17. Indikator Kompetensi (Pelaksanaan) di Bengkel Plambing

\begin{tabular}{cccccc}
\hline Jawaban $(\mathrm{N})$ & Frekuensi $(\mathrm{F})$ & N.F & Prosentase $(\%)$ & Rerata & Kategori \\
\hline 1 & 1 & 1 & 0,67 & & \\
2 & 13 & 26 & 8,67 & 3,61 & Baik \\
3 & 47 & 141 & 31,33 & & \\
4 & 71 & 284 & 47,33 & & \\
5 & 18 & 90 & 12,00 & & \\
Jumlah & 150 & 542 & 100,00 & & \\
\hline
\end{tabular}

Indikator lingkungan kerja pada pelaksanaan K3 di Bengkel Plambing reratanya adalah 3,28 yang berada dalam rentang nilai $2,60<\mathrm{x} \leq 3,40$ sehingga masuk dalam kategori cukup baik. Indikator lingkungan kerja pada pelaksanaan K3 di Bengkel Plambing disajikan dalam Tabel 18

Tabel 18. Indikator Lingkungan Kerja (Pelaksanaan) di Bengkel Plambing

\begin{tabular}{cccccc}
\hline Jawaban $(\mathrm{N})$ & Frekuensi $(\mathrm{F})$ & N.F & Prosentase $(\%)$ & Rerata & Kategori \\
\hline 1 & 11 & 11 & 4,07 & & \\
2 & 32 & 64 & 11,85 & 3,28 & Cukup Baik \\
3 & 123 & 369 & 45,56 & & \\
4 & 78 & 312 & 28,89 & & \\
5 & 26 & 130 & 9,63 & & \\
Jumlah & 270 & 886 & 100,00 & &
\end{tabular}

Indikator peralatan pada pelaksanaan K3 di Bengkel Plambing reratanya adalah 3,06 yang berada dalam rentang nilai $2,60<\mathrm{x} \leq 3,40$ sehingga masuk dalam kategori cukup baik. Data indikator peralatan pada pelaksanaan K3 di Bengkel Plambing disajikan dalam Tabel 19.

Tabel 19. Indikator Peralatan (Pelaksanaan) di Bengkel Plambing

\begin{tabular}{cccccc}
\hline Jawaban $(\mathrm{N})$ & Frekuensi (F) & N.F & Prosentase (\%) & Rerata & Kategori \\
\hline 1 & 12 & 12 & 6,67 & & \\
2 & 28 & 56 & 15,56 & & \\
3 & 84 & 252 & 46,67 & 3,06 & Cukup Baik \\
4 & 50 & 200 & 27,78 & & \\
5 & 6 & 30 & 3,33 & & \\
Jumlah & 180 & 550 & 100,00 & & \\
\hline
\end{tabular}

Indikator keterlibatan mahasiswa pada pelaksanaan K3 di Bengkel Plambing reratanya adalah 3,19 yang berada dalam rentang nilai $2,60<\mathrm{x} \leq 3,40$ sehingga masuk dalam kategori cukup baik. Data indikator keterlibatan mahasiswa pada pelaksanaan K3 tersebut disajikan dalam Tabel 20.

Tabel 20. Indikator Keterlibatan Mahasiswa (Pelaksanaan) di Bengkel Plambing

\begin{tabular}{cccccc}
\hline Jawaban $(\mathrm{N})$ & Frekuensi $(\mathrm{F})$ & N.F & Prosentase (\%) & Rerata & Kategori \\
\hline 1 & 4 & 4 & 3,33 & & \\
2 & 20 & 40 & 16,67 & 3,19 & Cukup Baik \\
3 & 49 & 147 & 40,83 & & \\
4 & 43 & 172 & 35,83 & & \\
5 & 4 & 20 & 3,33 & & \\
Jumlah & 120 & 383 & 100,00 & & \\
\hline
\end{tabular}

Indikator program penilaian resiko pada evaluasi K3 di Bengkel Plambing rerata sebesar 2,93 berada dalam rentang $2,60<\mathrm{x} \leq 3,40$ sehingga masuk kategori cukup baik. Indikator program penilaian resiko pada evaluasi K3 tersebut sebagaimana disajikan dalam Tabel 21. 
Tabel 21. Indikator Program Penilaian Resiko (Evaluasi) di Bengkel Plambing

\begin{tabular}{cccccc}
\hline Jawaban $(\mathrm{N})$ & Frekuensi $(\mathrm{F})$ & N.F & Prosentase $(\%)$ & Rerata & Kategori \\
\hline 1 & 0 & 0 & 0,00 & & \\
2 & 20 & 40 & 33,33 & 2,93 & Cukup Baik \\
3 & 27 & 81 & 45,00 & & \\
4 & 10 & 40 & 16,67 & & \\
5 & 3 & 15 & 5,00 & & \\
Jumlah & 60 & 176 & 100,00 & & \\
\hline
\end{tabular}

Indikator identifikasi bahaya pada evaluasi K3 di Bengkel Plambing reratanya adalah 2,70 yang berada dalam rentang nilai cukup baik. Data indikator identifikasi bahaya pada evaluasi K3 di Bengkel Plambing disajikan dalam Tabel 22 berikut: $2,60<\mathrm{x} \leq 3,40$ sehingga masuk dalam kategori

Tabel 22. Indikator Identifikasi Bahaya (Evaluasi) di Bengkel Plambing

\begin{tabular}{cccccc}
\hline Jawaban $(\mathrm{N})$ & Frekuensi $(\mathrm{F})$ & N.F & Prosentase $(\%)$ & Rerata & Kategori \\
\hline 1 & 2 & 2 & 3,33 & & \\
2 & 20 & 40 & 33,33 & 2,70 & Cukup Baik \\
3 & 33 & 99 & 55,00 & & \\
4 & 4 & 16 & 6,67 & & \\
5 & 1 & 5 & 1,67 & & \\
Jumlah & 60 & 162 & 100,00 & & \\
\hline
\end{tabular}

Indikator strategi pencegahan pada evaluasi K3 di Bengkel Plambing reratanya adalah 3,13 yang berada dalam rentang nilai $2,60<\mathrm{x} \leq 3,40$ sehingga masuk dalam kategori cukup baik. Data indikator strategi pencegahan pada evaluasi K3 di Bengkel Plambing disajikan dalam Tabel 23 berikut:

Tabel 23. Indikator Strategi Pencegahan (Evaluasi) di Bengkel Plambing

\begin{tabular}{cccccc}
\hline Jawaban $(\mathrm{N})$ & Frekuensi $(\mathrm{F})$ & N.F & Prosentase $(\%)$ & Rerata & Kategori \\
\hline 1 & 1 & 1 & 3,33 & & \\
2 & 5 & 10 & 16,67 & 3,13 & Cukup Baik \\
3 & 14 & 42 & 46,67 & & \\
4 & 9 & 36 & 30,00 & & \\
5 & 1 & 5 & 3,33 & & \\
Jumlah & 30 & 94 & 100,00 & & \\
\hline
\end{tabular}

Selain perolehan data di atas, responden juga memberikan komentar pada instrumen yang diantaranya adalah peningkatan kualitas K3, penambahan peralatan $\mathrm{K} 3$, perbaikan alat yang sudah tidak layak, peningkatan kejelasan jobsheet, penanganan terhadap kebisingan, pengawasan terhadap praktik mahasiswa, pemberian tanda bahaya pada alat, dan kurangnya kualitas maupun kuantitas peralatan. Indikator komitmen pada perencanaan $\mathrm{K} 3$ di Bengkel Batu reratanya adalah 3,24 yang berada dalam rentang nilai 2,60< $\mathrm{x} \leq 3,40$ sehingga masuk dalam kategori cukup baik. Data indikator komitmen pada perencanaan $\mathrm{K} 3$ di Bengkel Batu sebagaimana disajikan dalam Tabel 24 berikut:

Tabel 24. Indikator Komitmen (Perencanaan) di Bengkel Batu

\begin{tabular}{cccccc}
\hline Jawaban $(\mathrm{N})$ & Frekuensi $(\mathrm{F})$ & N.F & Prosentase (\%) & Rerata & Kategori \\
\hline 1 & 6 & 6 & 3,33 & & \\
2 & 35 & 70 & 19,44 & 3,24 & Cukup Baik \\
3 & 66 & 198 & 36,67 & & \\
4 & 55 & 220 & 30,56 & & \\
5 & 18 & 90 & 10,00 & & \\
Jumlah & 180 & 584 & 100,00 & & \\
\hline
\end{tabular}


Indikator komunikasi pada pelaksanaan

K3 di Bengkel Batu reratanya adalah 2,81.

Rerata tersebut berada dalam rentang nilai $2,60<\mathrm{x} \leq 3,40$ sehingga masuk dalam kategori cukup baik. Data indikator komunikasi pada pelaksanaan K3 di Bengkel Batu disajikan dalam Tabel 25 berikut:

Tabel 25. Indikator Komunikasi (Pelaksanaan) di Bengkel Batu

\begin{tabular}{cccccc}
\hline Jawaban $(\mathrm{N})$ & Frekuensi (F) & N.F & Prosentase (\%) & Rerata & Kategori \\
\hline 1 & 14 & 14 & 15,56 & & \\
2 & 22 & 44 & 24,44 & 2,81 & Cukup Baik \\
3 & 26 & 78 & 28,89 & & \\
4 & 23 & 92 & 25,56 & & \\
5 & 5 & 25 & 10,56 & & \\
Jumlah & 90 & 253 & 100,00 & & \\
\hline
\end{tabular}

Indikator kompetensi pada pelaksanaan

K3 di Bengkel Batu reratanya adalah 3,56.

Rerata tersebut berada dalam rentang nilai $3,40<\mathrm{x} \leq 4,2$ sehingga masuk dalam kategori baik. Indikator kompetensi pada pelaksanaan K3 di Bengkel Batu disajikan pada Tabel 26.

Tabel 26. Indikator Kompetensi (Pelaksanaan) di Bengkel Batu

\begin{tabular}{cccccc}
\hline Jawaban $(\mathrm{N})$ & Frekuensi (F) & N.F & Prosentase (\%) & Rerata & Kategori \\
\hline 1 & 3 & 3 & 2,00 & & \\
2 & 18 & 36 & 12,00 & & Baik \\
3 & 49 & 147 & 32,67 & 3,56 & \\
4 & 52 & 208 & 34,67 & & \\
5 & 28 & 140 & 18,67 & & \\
Jumlah & 150 & 534 & 100,00 & & \\
\hline
\end{tabular}

Indikator lingkungan kerja dalam dalam kategori cukup baik. Data indikator pelaksanaan K3 di Bengkel Batu reratanya lingkungan kerja pada pelaksanaan K3 di adalah 3,39. Rerata tersebut berada dalam Bengkel Batu disajikan dalam Tabel 27. rentang nilai $2,60<\mathrm{x} \leq 3,40$ sehingga masuk

Tabel 27. Indikator Lingkungan Kerja (Pelaksanaan) di Bengkel Batu

\begin{tabular}{cccccc}
\hline Jawaban $(\mathrm{N})$ & Frekuensi $(\mathrm{F})$ & N.F & Prosentase $(\%)$ & Rerata & Kategori \\
\hline 1 & 4 & 4 & 1,48 & & \\
2 & 42 & 84 & 15,56 & 3,39 & Cukup Baik \\
3 & 93 & 279 & 34,44 & & \\
4 & 108 & 432 & 40,00 & & \\
5 & 23 & 115 & 8,52 & \\
Jumlah & 270 & 914 & 100,00 & \\
\hline
\end{tabular}

Indikator peralatan pada pelaksanaan $\mathrm{K} 3$ di Bengkel Batu reratanya adalah 3,32 yang berada dalam rentang nilai $2,60<\mathrm{x} \leq 3,40$ Tabel 28. Indikator Peralatan (Pelaksanaan) di Bengkel Batu

\begin{tabular}{cccccc}
\hline Jawaban $(\mathrm{N})$ & Frekuensi (F) & N.F & Prosentase (\%) & Rerata & Kategori \\
\hline 1 & 4 & 4 & 2,22 & & \\
2 & 30 & 60 & 16,67 & & \\
3 & 68 & 204 & 37,78 & 3,32 & Cukup Baik \\
4 & 61 & 244 & 33,89 & & \\
5 & 17 & 85 & 9,44 & & \\
Jumlah & 180 & 597 & 100,00 & & \\
\hline
\end{tabular}

sehingga masuk dalam kategori cukup baik. Data indikator peralatan pada pelaksanaan $\mathrm{K} 3$ di Bengkel Batu disajikan dalam Tabel 28 berikut: 
Indikator keterlibatan mahasiswa pada pelaksanaan K3 di Bengkel Batu reratanya 3,30 berada dalam rentang $2,60<\mathrm{x} \leq 3,40$ sehingga masuk kategori cukup baik. Data indikator keterlibatan mahasiswa pada pelaksanaan K3 di Bengkel Batu disajikan dalam Tabel 29

Tabel 29. Indikator Keterlibatan Mahasiswa (Pelaksanaan) di Bengkel Batu

\begin{tabular}{cccccc}
\hline Jawaban $(\mathrm{N})$ & Frekuensi $(\mathrm{F})$ & N.F & Prosentase $(\%)$ & Rerata & Kategori \\
\hline 1 & 6 & 6 & 5,00 & & \\
2 & 25 & 50 & 20,83 & 3,30 & Cukup Baik \\
3 & 36 & 108 & 30,00 & & \\
4 & 33 & 132 & 27,50 & & \\
5 & 20 & 100 & 16,67 & & \\
Jumlah & 120 & 396 & 100,00 & & \\
\hline
\end{tabular}

Indikator program penilaian resiko pada evaluasi K3 di Bengkel Batu reratanya 3,08 dalam rentang nilai 2,60 $<\mathrm{x} \leq 3,40$ (cukup baik).

Data tersebut disajikan dalam Tabel 30 berikut:

Tabel 30. Indikator Program Penilaian Resiko (Evaluasi) di Bengkel Batu

\begin{tabular}{cccccc}
\hline Jawaban $(\mathrm{N})$ & Frekuensi $(\mathrm{F})$ & N.F & Prosentase (\%) & Rerata & Kategori \\
\hline 1 & 2 & 2 & 3,33 & & \\
2 & 14 & 28 & 23,33 & 3,08 & Cukup Baik \\
3 & 26 & 78 & 43,33 & & \\
4 & 13 & 52 & 21,67 & & \\
5 & 5 & 25 & 8,33 & & \\
Jumlah & 60 & 185 & 100,00 & & \\
\hline
\end{tabular}

Indikator identifikasi bahaya pada evaluasi K3 di Bengkel Batu reratanya adalah 2,92 berada dalam rentang nilai $2,60<\mathrm{x} \leq 3,40$ sehingga masuk dalam kategori cukup baik. Data indikator identifikasi bahaya pada evaluasi $\mathrm{K} 3 \mathrm{di}$ Bengkel Batu disajikan dalam Tabel 31 berikut:

Tabel 31. Indikator Identifikasi Bahaya (Evaluasi) di Bengkel Batu

\begin{tabular}{cccccc}
\hline Jawaban $(\mathrm{N})$ & Frekuensi $(\mathrm{F})$ & N.F & Prosentase $(\%)$ & Rerata & Kategori \\
\hline 1 & 1 & 1 & 1,67 & & \\
2 & 24 & 48 & 40,00 & 2,92 & Cukup Baik \\
3 & 18 & 54 & 30,00 & & \\
4 & 13 & 52 & 21,67 & & \\
5 & 4 & 20 & 6,67 & & \\
Jumlah & 60 & 175 & 100,00 & & \\
\hline
\end{tabular}

Indikator strategi pencegahan pada evaluasi K3 di Bengkel Batu reratanya adalah 2,90 berada dalam rentang nilai 2,60<x $\leq 3,40$ sehingga masuk dalam kategori cukup baik. Data indikator strategi pencegahan pada evaluasi K3 di Bengkel Batu disajikan dalam Tabel 32 berikut:

Tabel 32. Indikator Strategi Pencegahan (Evaluasi) di Bengkel Batu

\begin{tabular}{cccccc}
\hline Jawaban $(\mathrm{N})$ & Frekuensi $(\mathrm{F})$ & N.F & Prosentase $(\%)$ & Rerata & Kategori \\
\hline 1 & 2 & 2 & 6,67 & & \\
2 & 9 & 18 & 30,00 & 2,90 & Cukup Baik \\
3 & 10 & 30 & 33,33 & & \\
4 & 8 & 32 & 26,67 & & \\
5 & 1 & 5 & 3,33 & & \\
Jumlah & 30 & 87 & 100,00 & & \\
\hline
\end{tabular}


Selain perolehan data di atas, responden juga memberikan komentar di instrumen penelitian yang diantaranya adalah pergantian alat yang sudah tidak layak, peningkatan kualitas $\mathrm{K} 3$, pengawasan terhadap praktikan yang lebih baik, penempatan peralatan yang lebih rapi, kurangnya kesadaran mahasiswa terhadap K3, dan kondisi tempat praktik yang kurang luas. Hasil analisis pada masing-masing indikator setiap faktor di Bengkel Kayu, Bengkel Plambing, dan Bengkel Batu di atas apabila direkap seperti dalam Tabel 33 berikut:

Tabel 33. Kategori Penilaian Indikator Setiap Bengkel

\begin{tabular}{llccc}
\hline \multicolumn{1}{c}{ Faktor } & \multicolumn{1}{c}{ Indikator } & Bengkel Kayu & $\begin{array}{c}\text { Bengkel } \\
\text { Plambing }\end{array}$ & Bengkel Batu \\
\hline Perencanaan & Komitmen & Baik & Cukup Baik & Cukup Baik \\
Pelaksanaan & Komunikasi & Baik & Cukup Baik & Cukup Baik \\
& Kompetensi & Baik & Baik & Baik \\
& Lingkungan Kerja & Baik & Cukup Baik & Cukup Baik \\
& Peralatan & Baik & Cukup Baik & Cukup Baik \\
& Keterlibatan Mahasiswa & Baik & Cukup Baik & Cukup Baik \\
Evaluasi & Program Penilaian Resiko & Baik & Cukup Baik & Cukup Baik \\
& Identifikasi Bahaya & Baik & Cukup Baik & Cukup Baik \\
& Strategi Pencegahan & Baik & Cukup Baik & Cukup Baik \\
\hline
\end{tabular}

Hasil penelitian menunjukkan bahwa faktor Keselamatan dan Kesehatan Kerja (K3) di Bengkel Kayu, Bengkel Plambing, dan Bengkel Batu Pendidikan Teknik Sipil dan Perencanaan FT UNY masih perlu ditingkatkan. Hal tersebut dikarenakan masih terdapat potensi bahaya (kecelakaan) yang mungkin terjadi. Potensi bahaya tersebut hendaknya dikurangi atau bahkan dihilangkan agar tercipta K3 yang standar. K3 hendaknya dijadikan budaya kerja di bengkel, termasuk di Bengkel Kayu, Bengkel Plambing, dan Bengkel Batu. Budaya kerja tersebut dapat dilaksanakan dengan baik apabila seluruh pihak yang terlibat di bengkel dapat menjalankan K3 dengan penuh kesadaran.

Bengkel Kayu dan Plambing merupakan bengkel yang sangat besar terjadi potensi kecelakaan. Hal ini didukung oleh data survey PT Thiess (yang juga didampingi peneliti), salah satu perusahaan tambang yang sangat memperhatikan faktor $\mathrm{K} 3$ dalam aktivitas pekerjaan sehari-hari. Hasil tersebut menyatakan bahwa potensi terjadinya bahaya di Bengkel Kayu dan Plambing sangat mungkin mengingat kondisi bengkel saat ini dimana faktor-faktor K3 belum terpenuhi dengan baik. Sejalan dengan hal tersebut, PT Thiess dalam surveynya di Bengkel Batu menyatakan bahwa potensi bahaya yang dapat terjadi tidak terlalu besar. Hal ini terjadi karena di Bengkel Batu tidak ada peralatan mesin yang besar. Hanya saja ketika peneliti berdiskusi dengan surveyor dari PT Thiess, pada pekerjaan semacam di Bengkel Batu ini sangat besar potensi bahayanya ketika dilakukan dalam suatu pelaksanaan di proyek.

Hasil penelitian berupa angket yang diisi mahasiswa mengenai perencanaan, pelaksanaan, serta evaluasi K3 di Bengkel Kayu, Bengkel Plambing, dan Bengkel Batu menunjukkan bahwa masih perlunya peningkatan kualitas K3. Hal tersebut dibuktikan dengan komentar dan skor yang diberikan mahasiswa yang terdapat pada angket. Bengkel Kayu yang pada kenyataannya terdapat banyak mesin yang besar mendapatkan nilai yang masuk dalam kategori baik pada semua indikator masing-masing faktor. Dari hal tersebut dapat diinterpretasikan bahwa mahasiswa menganggap perencanaan, pelaksanaan, dan evaluasi ketika praktik sudah baik. Hanya saja nilai yang termasuk rendah di Bengkel Kayu adalah indikator peralatan dan identifikasi bahaya. Respon tersebut memang tidak salah karena beberapa peralatan terutama mesin yang terdapat di Bengkel Kayu sudah tidak lengkap seperti ketika kondisi awal dahulu. Hal tersebut akan menimbulkan potensi bahaya.

Selain itu, mahasiswa juga menginginkan perbaikan peralatan yang sudah tidak layak pakai 
karena seringnya digunakan untuk praktik. Indikator identifikasi bahaya di Bengkel Kayu juga dirasa kurang. Keadaan poster dan tanda peringatan bahaya selain memang kurang juga sudah usang. Oleh karena itu, mahasiswa menginginkan perbaikan pada indikator tersebut. Bengkel Plambing yang juga terdapat beberapa peralatan mesin berat dinilai mahasiswa dalam keadaan cukup baik kecuali indikator kompetensi yang mendapat kategori baik. Hal tersebut tentunya perlu diperhatikan mengingat besarnya potensi bahaya yang terdapat di Bengkel Plambing. Identifikasi bahaya, program penilaian resiko, dan komunikasi merupakan indikator yang nilainya rendah diantara indikatorindikator lainnya. Dua indikator pada faktor evaluasi masuk dalam nilai rendah. Hal tersebut memang terjadi di Bengkel Plambing yang kurang daftar identifikasi serta tingkat bahayanya. Selain itu mahasiswa juga menginginkan perbaikan serta penambahan peralatan yang erat kaitannya dengan K3.

Indikator-indikator di Bengkel Batu juga dinilai mahasiswa cukup baik kecuali indikator kompetensi yang mendapat kategori baik. Hanya saja penilaian tersebut tidak terlalu mengkhawatirkan karena potensi kecelakaan besar di Bengkel Batu cukup kecil. Hal tersebut tidak lepas dari kondisi di Bengkel Batu yang hampir tidak pernah terjadi kecelakaan yang sifatnya membahayakan. Jenis kecelakaan yang biasa terjadi di Bengkel Batu hanya kecelakaan kecil saja. Akan tetapi hal tersebut tidak boleh diabaikan karena potensi kecelakaan kerja yang mungkin terjadi ketika di proyek cukup besar.

Pencapaian K3 yang baik perlu usaha yang terencana dan sitematis. Pihak yang terkait di Bengkel Kayu, Bengkel Plambing, dan Bengkel Batu perlu menerapkan budaya K3 dalam praktik sehari-hari. Kebijakan untuk menerapkan K3 perlu dibuat agar dosen, teknisi, maupun mahasiswa mematuhi pelaksanaannya. Peraturan atau tata tertib pada masing-masing bengkel perlu untuk selalu ditekankan dalam setiap praktik. Hal tersebut dilakukan agar praktikan selalu memperhatikan K3 sehingga dapat bekerja dengan aman. Dosen dan teknisi hendaknya selalu mengingatkan mahasiswa agar dalam bekerja selalu memperhatikan faktor K3. Arahan tersebut hendaknya dilakukan dengan penuh keteladanan. Dosen dan teknisi juga diharuskan dapat memberi contoh kepada mahasiswa akan pentingnya $\mathrm{K} 3$. Hal tersebut salah satunya dapat dilakukan dengan perilaku tertib bekerja menggunakan Alat Pelindung Diri (APD). Hal ini sangat mudah diucapkan tetapi sulit dilakukan ketika praktik terutama di bengkel. Dosen dan teknisi hendaknya menyadari bahwa tanpa keteladanan, mental mahasiswa untuk peduli terhadap K3 akan sulit terbentuk.

Pengetahuan mengenai K3 penting untuk diketahui oleh praktikan (mahasiswa, dosen, dan teknisi). Praktikan hendaknya mengetahui bahwa bahaya dapat terjadi sewaktu-waktu sehingga perlu untuk selalu memperhatikan K3. Praktikan sebaiknya juga memahami potensi bahaya sekecil apapun yang dapat terjadi terhadap pekerjaan yang dilakukannya. Untuk itu di Pendidikan Teknik Sipil dan Perencanaan perlu diadakannya mata kuliah yang khusus membahas K3 maupun menyertakan aspek K3 dalam setiap mata kuliah.

Potensi kecelakaan kerja hampir selalu ada ketika bekerja, baik potensi dari kelalaian manusia maupun kondisi bengkel. Menyadari adanya potensi kecelakaan kerja tersebut hendaknya kita selalu berhati-hati dalam bekerja. Hal tersebut termasuk ketika kita menggunakan peralatan dalam bekerja terutama mesin. Penggunaan peralatan dalam bekerja sebaiknya sesuai dengan Standard Operating Procedure (SOP). Hal tersebut dilakukan agar keselamatan alat dan manusia dapat terjamin. Potensi kecelakaan kerja di bengkel masih dapat terjadi walaupun kita sudah bekerja sesuai prosedur. Hal tersebut terjadi karena kecelakaan kerja sering terjadi akibat ketidaksengajaan. Dosen dan teknisi hendaknya selalu mengawasi mahasiswa ketika praktik. Prosedur kerja yang baik dan aman dijelaskan ketika praktik, sementara itu pengawasan dilakukan untuk meminimalisir kesalahan mahasiswa.

Kecelakaan kerja yang pernah terjadi 
walaupun sudah diantisipasi sebelumnya, hendaknya dijadikan sebagai sarana refleksi oleh praktikan. Pihak-pihak yang terkait di bengkel (dosen dan teknisi) dapat menjadikan kecelakaan tersebut sebagai pengalaman yang tidak boleh terjadi lagi. Langkah tersebut dapat dilakukan dengan merekam kecelakaan yang terjadi, penyebab kecelakaan, maupun akibat dari kecelakaan. Rekaman kecelakaan tersebut nantinya disampaikan kepada mahasiswa yang selalu berganti.

\section{SIMPULAN}

Berdasarkan hasil dan pembahasan dalam penelitian ini dapat disimpulkan bahwa: (1) Perencanaan K3 di Bengkel Kayu, Bengkel Plambing, dan Bengkel Batu Jurusan Pendidikan Teknik Sipil dan Perencanaan FT UNY masih perlu diperbaiki agar lebih matang serta sistematis. Hal tersebut penting dilakukan mengingat adanya potensi bahaya yang timbul akibat kondisi bengkel saat ini. (2) Pelaksanaan K3 di Bengkel Kayu, Bengkel Plambing, dan Bengkel Batu Pendidikan Teknik Sipil dan Perencanaan FT UNY masih perlu ditingkatkan. Hal tersebut dikarenakan kebijakan dan perencanaan yang belum baik sehingga dalam pelaksanaannya perlu usaha yang lebih. (3) Evaluasi K3 di Bengkel Kayu, Bengkel Plambing, dan Bengkel Batu Pendidikan Teknik Sipil dan Perencanaan FT UNY perlu dilakukan secara simultan. Pemantauan dan evaluasi penting dilakukan oleh pihak penentu kebijakan, dosen, dan teknisi. Hal tersebut harus dilakukan oleh pihak yang kompeten terhadap K3 serta kondisi bengkel. (4) Budaya Keselamatan dan Kesehatan Kerja (K3) di Bengkel Kayu, Bengkel Plambing, dan Bengkel Batu Pendidikan Teknik Sipil dan Perencanaan FT UNY masih perlu ditingkatkan. Hal tersebut hendaknya diawali dengan penetapan kebijakan mengenai K3 sehingga dapat diterapkan dalam proses dan praktik selanjutnya. (5) Faktor peninjauan dan peningkatan kinerja K3 perlu dilakukan untuk menjamin kesesuaian dan efektivitas penerapan sesuai Sistem Manajemen K3.

\section{DAFTAR RUJUKAN}

1996. Peraturan Menteri Tenaga Kerja Nomor 05/MEN/1996 Tentang Sistem Manajemen Keselamatan dan Kesehatan Kerja. Jakarta: Kementerian Tenaga Kerja Republik Indonesia

2012. Peraturan Pemerintah Republik Indonesia Nomor 50 Tahun 2012 Tentang Penerapan Sistem Manajemen Keselamatan dan Kesehatan Kerja. Jakarta: Kementerian Sekretariat Negara Republik Indonesia

Indrayani dan Ika Sulianti. 2014. Kajian Penerapan Kesehatan dan Keselamatan Kerja (K3) dalam Proses Belajar Mengajar di Bengkel dan Laboratorium Politeknik Negeri Sriwijaya. PILAR Jurnal Teknik Sipil. Volume 10 No. 1 Maret 2014

Mario Merly Herman. 2007. Kajian Penerapan Pelaksanaan K3 pada Siswa-siswa SMK Bidang Keahlian Teknik Bangunan di Malang. Skripsi. Universitas Negeri Malang

Putut Hargiyarto. 2010. Analisis Kondisi dan Pengendalian Bahaya pada Bengkel Atau Laboratorium untuk Menjamin Keselamatan dan Kesehatan Kerja di Sekolah Menengah Kejuruan. [Experiment/ Research] (Unpublished). Universitas Negeri Yogyakarta

Ridley, John. 2009. Kesehatan dan Keselamatan Kerja. Alih Bahasa: Soni Astranto, Editor Lemeda Simarmata. Jakarta: Erlangga

Soehatman Ramli. 2009. Pedoman Praktis Manajemen Resiko dalam Perspektif K3 OSH Risk Management. Jakarta: PT. Dian Rakyat

Tarwaka. 2008. Keselamatan dan Kesehatan Kerja Manajemen dan Implementasi K3 di Tempat Kerja. Surakarta: Harapan Press 